\title{
Los continos de don Cristóbal Colón
}

\author{
ISTVÁN SZÁSZDI LEÓN-BORJA *
}

\section{RESUMEN ABSTRACT}

La presente investigación ha procurado dar a conocer a un grupo de servidores de Cristóbal Colón, mal conocido hasta ahora. Los continos colombinos eran oficiales, de gran lealtad y privanza, que muchas veces pertenecian a la nobleza urbana castellana. Los continos del Almirante fueron los precursores de los criados de los Virreyes de Indias. No todos alcanzaron el éxito social en el Nuevo Mundo, pero tenemos constancia que algunos lograron fama, poder $y$ buenos enlaces en la sociedad antillana.
The present paper is the description of the vital role of a group of men, poorly studied until the present date, that served Christopher Columbus, whose faithfulness and loyalty cause our admiration. Far from being ordinary servants, these officers were well qualified and belonged most of the times to the urban nobility. The continos of Columbus were the predecessors of the colonial criados of the Spanish Viceroys in the New World. Their success in colonial society should not be taken for granted, but some of them became notorious and were well married.

* Universidad de Valladolid. 
En los últimos veinte años la historiografía parece volver a interesarse por las instituciones y la organización de la Casa Real ${ }^{1}$. Otro tanto, más recientemente, parece empezar a ocurrir con los criados de los Virreyes de Indias y sus Cortes ${ }^{2}$. Para comprender su evolución es necesario remontarnos a la Corte de Castilla y de Aragón y detenernos en un tipo de servidores regios, fundamentales para nuestro estudio: los Continos Reales.

\section{LOS CONTINOS REALES Y EL NUEVO MUNDO.}

Los Continos eran oficiales nombrados directamente por los Reyes con funciones indeterminadas para que prestaran sus servicios allí donde sus señores lo deseaban, con variadas competencias, donde fueran fieles ejecutores de la voluntad real. Podían estar bajo el mandato de otro oficial, como en el caso del Almirante-Visorrey en el Segundo Viaje, pero ello era consecuencia de la voluntad real y sólo mientras ésta lo demandara ${ }^{3}$. Característico de los Continos es su servicio continuado al Rey o a la Reina, juraban su cargo como tales oficiales y percibían quitaciones por sus servicios, cuyas cartas eran incorporadas a los libros de los Contadores Mayores. Por su familiaridad con los Reyes muchas veces fueron llamados criados, siendo esto cierto de algunos que sí lo fueron, por haber sido criados en la Casa Real a la cual habían entrado a formar parte desde temprana edad ${ }^{4}$. Su disponibilidad hacia de ellos oficiales eficientes de máxima utilidad para el cumplimiento de los deseos reales, que recibían instrucciones escritas para el ejercicio de su misión. Pertenecían muchas veces a familias con tradición en la continería, unas veces eran hi-

\footnotetext{
David ToRres Sanz, La administración central castellana en la Baja Edad Media (Valladolid, 1982). Luis Vicente Díaz Martín, Los Oficiales de Pedro I de Castilla (Valladolid, 1987). Rafael Domínguez Casas, Arte y etiqueta de los Reyes Católicos. Artistas, residencias, jardines y bosques (Madrid, 1993). José Manuei Nieto SoRIA (Dir.), Origenes de la Monarquía Hispana: Propaganda y Legitimación (CA. 1400-1520) (Madrid, 1999). Rita Costa GoMES, A Corte dos Reis de Portugal no final da ldade Média (Lisboa, 1995). Tomás de Montagut I Estragues, «Els funcionaris i I'administració reial a Catalunya (segles XIII-XIV)»: La societat barcelonina a la Baixa Edat Mitjana (Barcelona, 1983), pp. 137-150.

2 Nelly Porro Girard, «Los criados en las Indias del quinientos: del servicio privado a la función pública»: Actas y Estudios del XI Congreso del Instituto Internacional de Historia del Derecho Indiano, IV (Buenos Aires, 1997), pp. 91-123. Inés RodríGuEz LóPEz, «Continos de Aragón en la empresa colombina»: VII Congreso Internacional de Historia de América, 1 (Zaragoza, 1998), pp. 651-664.

3 Rodriguez, "Continos» (nota 2), p. 654.

4 István SzÁszd, "Gobierno e inicio de la recaudación áurea en el Nuevo Mundo»: Anuario de Estudios Americanos, LIV-2 (Sevilla, 1997), p. 622. Los Continos de los Reyes
} 
dalgos y otras veces a poderosas familias de la gran nobleza ${ }^{5}$. El oficio de Contino Real se encontraba regulado por una Ordenanza hoy perdida ${ }^{6}$.

La relación de los Continos con las Yndias se remonta a la preparación del viaje de 1492, cuando los Reyes enviaron a Moguer y a Palos, en «la costa de la mar del Andalusya», a Joan de Peñalosa, Contino de la Casa Real para hacer entregar a Colón las carabelas necesarias para su viaje «en el Mar Océano» ?.

Durante aquél tuvo importante relieve el contino Rodrigo de Escobedo. Era el Escribano de la Armada, pero a diferencia de la opinión tradicional consideramos que la razón por la que fue escogido por Cristóbal Colón como su Lugarteniente y Justicia con mandato sobre los demás hombres de Navidad tuvo que ver no sólo con sus méritos personales sino por ser Contino de la Casa de la Reina ${ }^{8}$. Fuera cierto o no que era pariente de fray Juan Pérez, su relevancia se encontraba en pertenecer a este grupo de oficiales reales que tenían por fin el servir de ojos y manos de los Reyes. Ésta será una pauta en el gobierno temprano del Nuevo Mundo, el deseo de los Reyes de la participación de sus continos.

Cabe señalar que durante su reinado don Fernando y doña Ysabel usaron de los continos con gran frecuencia, así proliferaron continos con nombramientos de corregidores, con misiones de naturaleza diplomática, de carácter económico y militar, cuando los Reyes necesitaban asegurarse del cumplimiento de su mandato. Por esto era razonable escoger a Rodrigo de Escobedo como Justicia y Teniente del Visorrey-Gobernador, quien era además letrado. Y por ser persona acostumbrada a obedecer a Sus Altezas se le suponía apto para mandar a los hombres de Navidad. Escobedo tenía el cometido de obtener toda la información posible del secreto de la tierra por boca del cacique amigo Guacanagarí como de explorar la costa. Pronto se probó ineficaz a la hora de mantener la paz entre los cristianos no pudiendo sofocar la sedición de los vizcaínos.

El Segundo Viaje de Cristóbal Colón bien puede llamarse el "Viaje de los Continos» dado su número y el relieve que tuvieron en los hechos que

5 RodRiguez, «Continos» (nota 2), p. 654.

- Comunicación personal de la licenciada doña Inés Rodríguez López quien se halla ocupada, en el presente, en la elaboración de su tesis doctoral que versa sobre los Continos Reales en Castilla.

7 Colección Documental del Descubrimiento (1470-1506) [CDD.], Ed. Juan Pérez dE TudelA, Carlos Seco Serrano, Ramón Ezquerra Abadía y Emilio López Oto, I (Madrid, 1994), pp. 94-97.

8 István SzÁszDI, «Rodrigo de Escobedo, Justicia, Teniente del Virrey Gobernador de las Yndias, y la Ynstruçión del Fuerte Navidad»: Novahispania, 6 (México, en vías de publicación). Szászdi, «Gobierno» (nota 4), pp. 617-622. 
lo jalonaron ${ }^{9}$. Los Reyes enviaron a un buen número de estos servidores extraordinarios para asegurar la efectividad de aquella armada expedicionaria a las tierras del Gran Can. La reacción inicial de Colón fue contraria, pues veía en aquella decisión una intromisión de los monarcas en su virreinato, ello dio pie a sus reiteradas peticiones de llevar sus propios continos. Los Reyes temieron que ello fuera causa de conflicto con los propios continos que enviaban, pero por dar placer a Colón, ante su insistencia, le otorgaron lo que pedía. Pero no nos adelantemos.

Los Continos Reales que más importancia tuvieron en aquella empresa fueron Pedro Margarit, Antonio de Torres, Melchor Maldonado, Alonso Sánchez de Carvajal, y Juan de Luján. Mientras Alonso Sánchez Carvajal, y Juan de Luján, regidor de Baeza, fueron nombrados miembros del Consejo a cuya cabeza nombró el Virrey a su hermano Diego Colón y a fray Bernal Buyl; Pedro Margarit se convirtió en teniente militar de don Cristóbal Colón, con la misión de asegurar el fuerte de Santo Tomás con título de alcaide de aquella fortaleza y pacificar la tierra de las minas ${ }^{10}$. Melchor Maldonado, sevillano muy considerado por los Reyes, que había tenido experiencia en la negociación diplomática italiana, fue obligado a hacer el viaje con el Almirante-Visorrey. En palabras de Pedro Mártir de Anglería, refiriéndose a sus conocimientos cosmográficos, a su regreso a Castilla: «En este viaje no ha venido ninguno que acerca de esta materia merezca más crédito que él» ${ }^{11}$. Antonio de Torres también era persona de la mayor garantía para los Reyes, hermano del Ama del Príncipe don Juan desempeñó numerosas misiones delicadas y relevantes durante su vida.

\section{LOS CONTINOS DEL VIRREY EN EL SEGUNDO VIAJE.}

La decisión de los Reyes de enviar sus continos provocó el que Cristóbal Colón demandara el llevar otros propios suyos. Una decisión, pues, que era indicio que Colón utilizaría la gran autonomía capitulada en Santa Fe para convertir las Antillas en su celoso señorío. Tanto los prelados - con sus familiares- como las grandes casas nobles castellanas te-

9 SZÁSZDI, «Gobierno» (nota 4), p. 624.

- Rodriguez, «Continos» (nota 2), p. 654-664.

11 Pedro MartiR de Angleria, Décadas del Nuevo Mundo (Madrid, 1989), p. 25. Para conocer en detalle la hoja de servicios del contino Maldonado véase: István SzÁszoI, «Guatiao, los primeros Tratados de Indias", Actas y Estudios del IX Congreso Internacional del Instituto de Historia del Derecho Indiano (Madrid, 1991), pp. 411-415. 
nían a su servicio continos, quienes eran un tipo especial de servidores. El flamante Virrey no podía ser menos.

Don Cristóbal Colón quería tener continos, no como para poseer simples criados asalariados que ornaran su corte virreinal, sino como militares que estrictamente bajo su control hicieran mantener la autoridad de su persona. El Virrey quería organizar un ejército particular que ponía en peligro la unidad de las armas cristianas en el Nuevo Mundo, no había tenido suficiente escarmiento. El problema no era nuevo, el desastre de la Navidad, del primer asentamiento cristiano se debió a aquella desunión, de la cual el propio Colón era el primer responsable.

Por ello la primera reacción de los Reyes es negativa ante tal pretensión de su Almirante. El 4 de agosto de 1493, desde Barcelona, Sus Altezas escribieron a su consejero el Arcediano de Sevilla, don Juan Rodríguez de Fonseca, quien era el encargado de armar la flota colombina:

"Dos letras vuestras recibimos que nos envió Francisco Pinelo... cuanto a los continos que decis que toma el Almirante de las Indias, bien fue lo que le distéis que para este viaje no ha menester tomar continos algunos, pues todos los que allá van por nuestro mandado han de facer lo quél en nuestro nombre les mandare, y facer apartamiento de suyos y ajenos podría traer mucho inconveniente; pero si para su acompañamiento quisiere llevar algunos que lleven nombre de suyos, bien podrá llevar fasta diez escuderos en cuenta de los cincuenta escuderos que han de ir, e otras veinte personas en cuenta de las mil personas que han de ir, y a éstas se pague su sueldo como a las otras segund de acá fue ordenado; que lleve algunas más que éstas, fágase como vos ge lo hobiéredes dicho»" ${ }^{12}$.

Pero pocos días más tarde, el 18 de agosto, los Reyes volvieron sobre el particular, y le mandaron a Fonseca que limara asperezas con Colón en todo lo que se refiriera a la negociación indiana, pues en palabras de los Reyes:

«pues esa armada va a su cargo, razón es que a su voluntad sea sin que con él se ponga ninguno en en puntos de diferencia: por ende por servicio nuestro que esto miréis mucho, y lo contentéis cuanto más pudiéredes."

En esa carta conciliadora, tras el incidente entre Colón y Juan de Soria, los Reyes le mandaban a su Consejero:

\footnotetext{
12 Martín Fernández de NavarRete, Obras de, Colección de los Viajes y Descubrimientos que hicieron por mar los españoles desde fines del siglo XV. Ed. y estudio preliminar de D. Carlos Seco Serrano, I (Madrid, 1954), p. 354.
} 
«y cuanto a los continos quél quiere llevar, ya sabéis quel otro día vos escribimos que él pueda llevar diez escuderos a pie e otros veinte hombres que sean suyos, $y$ a esos se les pague como a los otros, e entren en el número de la gente que ha de ir... Y pues todos van a su gobernación y han de facer lo quél les mandare, non es más menester..." ${ }^{13}$.

Una gran generosidad inhabitual de los Reyes, pues éstos se comprometían a pagar a los continos del Virrey como si fueran propios. El mismo día del mes de agosto, aquéllos firmaron una Real Cédula dirigida a Juan de Soria, que era Secretario del Príncipe y habia sido nombrado Contador de la Armada del Segundo Viaje, y que tenía poderes de los Contadores Mayores. En ella los Reyes abordaron el tema de nuevo, pues le habían escrito anteriormente sobre el particular, instruyéndole al Contador:

\begin{abstract}
"Y cuánto a los continos quel dicho Almirante de las Indias dice que quiere llevar, el otro día vos escribimos que de escuderos se le pagasen diez escuderos de a pie, e otras veinte personas de los otros, de manera que lleve treinta personas suyas, y pues toda la gente ha de ir a su ordenación y gobernación, todos harán lo quél les mandare; y pues su partida está tan al cabo, Nos vos mandamos que procuréis cómo vaya con mucho contentamiento, porque asi lo queremos e nos place..." 14 .
\end{abstract}

Uno puede imaginar que el motivo de Colón al insistir en tener sus propios continos militares obedecía al temor de un ataque portugués en la isla de Haití. La carabela que D. Joâo II de Portugal había enviado desde la Isla de la Madera, era una clara señal que la confrontación con Portugal era casi inevitable, y que la argumentación jurídica estaba unida a la de las armas ${ }^{15}$. No olvidemos que cuando hablamos de escuderos hablamos de hombres de armas, función que debían cumplir tales continos. Según parece Colón quería poner sus escuderos en todos los navíos pero los Reyes sólo le concedieron el poner uno suyo en cada nao de la armada ${ }^{16}$. La función de éstos no era de naturaleza económica sino la de mantener el orden en las naos como representantes del Virrey. El Escudero era la autoridad en cada vaso junto al Escribano y al Oficial de los Contadores Mayores que debía ir en cada uno, según mandaron los Reyes. El recuerdo de los motines del Viaje del Descubrimiento hacía que Colón tomara

13 Ibidem, p. 355.

14 Ibidem, p. 356.

15 Sobre estos temores ver de Ádám SzÁSZDI NAGY e István SZÁSZDI LEÓN-BORJA, «La Crisis Luso-Castellana de 1493 por el Mar Oçéano": Castilla y Portugal en los albores de la Edad Moderna, Rosa Espinosa-Julia MONTENEgro (Coord.), (Valladolid, 1997), pp. 109-123.

16 Demetrio Ramos Pérez, El conflicto de las Lanzas Jinetas. El primer alzamiento en tierra americana, durante el segundo viaje colombino, (Valladolid, 1982), p. 36. 
sus precauciones. Eran estos escuderos continos jóvenes hidalgos reclutados con la ayuda de Juan Rodríguez de Fonseca, cuando los Reyes le dieron la orden de facilitar los deseos de Colón. El salario de los escuderos continos del Virrey alcanzaba los 900 maravedís al mes, por lo menos eso es lo que cobró Pedro de Terreros desde el 27 de agosto de 1493 hasta que volvió del Nuevo Mundo, el 11 de junio de 1496. Gracias a doña Alice Gould conocimos la lista de los continos de Colón en el Segundo Viaje ${ }^{17}$ :

\author{
1. Arroyal, Pedro de \\ 2. Barrasa, Francisco \\ 3. Cañizares, Diego de \\ 4. Cerón, Juan \\ 5. Comillas, Luis de \\ 6. Córdoba, Ferrando de \\ 7. Escobar, Diego de \\ 8. Gallego, Pedro \\ 9. Lanuza, Martín de \\ 10. Mayorga, Luis de \\ 11. Meneses, Alvar Pérez de \\ 12. Molina, Juan Pérez de \\ 13. Morales, Bartolomé de \\ 14. Muñoz, Aloriso \\ 15. Porras, Francisco de \\ 16. Porras, Gonzalo de \\ 17. Troche, García de \\ 18. Sepúlveda, Lope de \\ 19. Terreros, Pedro de \\ 20. Torres, Cristóbal \\ 21. Vargas, Francisco \\ 22. Venegas, Juan.
}

Cuando en la primera mitad del siglo publicó esta lista en el Boletín de la Real Academia de la Historia, evitó adelantar la fuente documental de este valioso hallazgo por estar preparando el texto de un libro dedicado al Segundo Viaje que desgraciadamente nunca vio la luz ${ }^{18}$. La referencia del documento permaneció olvidada, hasta fecha reciente, en el fichero que

17 Alice B. Gould, Nueva Lista documentada de los Tripulantes de Colón en 1492 (Madrid, 1984), pp. 378-390. En la página 378 se refiere a "las listas hechas por el mismo Fonseca" al determinar cuánto ganaba Terreros entre el 27 de agosto de 1493 y su regreso a Castilla el 11 de junio de 1496, lo que es una clara alusión a "Relación de Cuentas de los maravedís que las presonas en ella contenida han de aver que les son devidas del sueldo que ganaron en el Viaje de las Yndias" a que haremos alusión inmediatamente.

18 Así lo declara Ballesteros. [Antonio BALlesteros BeretTA, Cristóbal Colón y el Descubrimiento de América, II (Barcelona, 1945), p. 162.] 
dejó la historiadora norteamericana, custodiado en la sala con su nombre en la Real Academia de la Historia en Madrid ${ }^{19}$. El expediente se compone de una Real Cédula dirigida a Fonseca, fechada en Ávila a 3 de noviembre de 1497, con el traslado de otras dos incorporadas también dirigidas al dicho Obispo de Badajoz, una fechada en Burgos a 13 de octubre de 1496 y otra en la villa de Medina del Campo a 12 de septiembre de 1497. Documentación que contiene la relación de cuentas con los pagos de los salarios de los tripulantes y otras datos de interés. El expediente que debe identificarse como "Relación de Cuentas de los maravedís que las presonas en ella contenida han de aver que les son devidas del sueldo que ganaron en el Viaje de las Yndias» ${ }^{20}$ y que llamaré de aquí en adelante "Relación de Cuentas de Salarios Debidos", está incompleto. Según daba fe el propio Obispo Pacense, don Juan Rodríguez de Fonseca a Sus Altezas, en la Foja 26r., el expediente estaba compuesto originalmente de

«quarenta e nueve fojas de pliego de papel todas raydas e señaladas e demas de las personas en esta relaçion contenidas quedan otras muchas personas que en esta relación no van escriptas... »21.

Hoy en día el expediente tiene 28 Fojas, pero en realidad las cuentas personales sólo alcanzan hasta la Foja 25v. Como observó Miss Alice Gould, la «Relación de Cuentas de Salarios Debidos» consigna la muerte temprana de los continos Gallego y Venegas. Mantendré la numeración alfabética para los continos del Virrey que estableció Miss Gould, aunque ésta sea artificial por ir desordenados en las fojas del expediente, en reconocimiento a su memoria.

Mas ésta no fue la última vez que el Rey envió a sus continos a las Yndias. Entre las distintas ocasiones en que la Corona hizo uso de estos criados con comisiones, los encontramos en la Armada de Pedrarias Dávila a Tierra Firme en $1513^{22}$.

19 El documento se encuentra en el Archivo General de Simancas, Sección de Contaduría Mayor de Cuentas, Primera Época, legajo 98. María Montserrat León Guerrero, publicó su transcripción en el cuadernillo Segundo Viaje de Colón, nueva documentación (Valladolid, 1998). La Sita. León localizó el documento que ha nombrado "Gente del Segundo Viaje», gracias a la consulta del fichero de Miss Alice.

20 Así lo describe a los Reyes el propio don Juan Rodríguez de Fonseca.

21 Así lo declara Fonseca en la la Foja 26 r.

22 Pasaron entonces Sancho Gómez de Córdoba, Francisco de Soto, y Diego de Lodueña. [Manuel SERRANo y SANz OSB., Orígenes de la Dominación Española en América. Estudios Históricos (Madrid, 1918), p. CCCXXXVII. María del Carmen MENA GARcía, Sevilla y las flotas de Indias. La gran Armada de Castilla del Oro (1513-1514) (Sevilla, 1998), pp. 78, 84.] Según esta última autora Soto era natural de Olmedo. 


\title{
III. LOS CRIADOS DEL VIRREY.
}

Habiendo identificado a los continos colombinos por medio de la "Relación" podemos seguir su trayectoria, reconstruyendo su hoja de servicios. Ofreceremos algunas noticias sorprendentes. Comencemos por decir que contino se consideraba, en la Castilla de finales del siglo $\mathrm{xv}$, como sinónimo de criado muy a menudo. Una de las ocupaciones más corrientes de los Continos Reales fue el servir como comisarios - de tener una comisión-, corregidores, gobernadores, embajadores, veedores, guardas, capitanes, y un largo etcétera. Ocupaban oficios y cargos mientras ésa fuera la voluntad de los Reyes. El modelo de los Continos Reales es el que marcará la andadura de los continos del Virrey, quien pronto se verán confusamente tratados como "criados" de éste. Es por tanto, el contino colombino, el directo precedente de los criados de los Virreyes indianos posteriores.

Los continos del Virrey juraron su oficio, conociendo y comprometiéndose a cumplir la Ordenanza de Continos, que en imitación a aquélla de los Continos Reales debieron tener, previamente a ser tomados como tales por su señor.

Veamos algunos ejemplos, Pedro de Terreros, quien según Miss Alice Gould fue el único que con Colón participara en los Cuatro Viajes colombinos, aparece en la "Relación de Cuentas de Salarios Debidos" en un asiento que se inicia:

\begin{abstract}
«Pedro de Terreros asentaronsele nueve çientos maravedis de sueldo cada mes por Escudero contino del Almirante don Xristoval Colon desde XXVI de agosto de XCIII años hasta XI de junio de XCVI años que boluio de las Yndias a Caliz..., ${ }^{23}$.
\end{abstract}

23 C.M.C. - 1a, E. f. 25v. En el "Asiento de Pagos que se hicieron a personas que fueron con sueldo a las Indias", fechado entre abril y mayo de 1498, figura la cantidad que se debía al Mayordomo del Almirante, Iohan Antonio, quien percibía el mismo salario que el Maestresala. El asiento de Terreros dice así: «Pedro de Terreros maestresala del Almirante ovo de aver treynta maravedis de sueldo cada dia que montan al año diez mill e ochoçentos maravedis desde el primero de mayo de nouenta y ocho años fasta». Al margen se escribió : «Ojo. Deue el dicho Pero de Terreros MIIIM XCV maravedis que el deuia al Almirante don Christoual Colon y se dio librança dellos al Almirante para la Corte de que esta su treslado en los treslados de cuentas, e cobrolos el dicho Pedro de Terreros en la Corte por la relacion que a el se dio de su cuenta y no se ha de pagar sueldo fasta que estos se le descuenten". A continuación, en las misma nota, se añadió: «Pedro de Arroyal camarero del Almyrante ovo de aver treynta maravedis de sueldo cada dia que montan al año diez mill e ochocientos maravedis desde el primero de mayo de noventa $y$ ocho años fasta. Rescibyo mas el dicho Anton Marino por el dicho Pedro de Arroyal dos mill e çiento e sesenta maravedis para su mantenimiento de seys meses a razon de dose maravedis cada dia por el dicho libramiento". [CDD. II (nota 7), pp. 1075-1076]. Como hemos visto Arroyal figura en la "Relación de Cuentas de Salarios Debidos", en calidad de "Escudero contino del Almirante don Xrtoual Colon", (fol. 21v). 
Cuando Terreros aparece de nuevo en la documentación es para testificar la continentalidad de Cuba, el 12 de junio de 1494. En la famosa información se le menciona en compañía de López de Çúñiga como:

"testygos que fueron presentes a ver jurar a todos e a cada vno por sy de los suso dichos segund y en la manera que de suso se contyene Pedro de Terreros, Maestresala del dicho señor Almirante, e Yñigo Lópes de Çuñiga, trinchante, criados del señor Almirante..." ${ }^{24}$.

Pedro de Terreros fue Capitán de la carabela Santa María de Guía, la nave capitana donde iba el propio Almirante en el Tercer Viaje. Por ser contino del Virrey, y no por otra razón, éste le delegó el honor de tomar posesión en nombre de los Reyes de Tierra Firme ${ }^{25}$. Por ser su Escudero contino estuvo junto al Virrey enfrentado a Francisco Roldán en los sucesos de la Española. También fue quien aseguró a Roldán de la buena fe del Almirante cuando Colón quiso entrevistarse con él. En el Cuarto Viaje fue Capitán del navío Gallego, y fue Terreros, también, a quien escogió el Almirante para pedir en su nombre al Gobernador frey Nicolás de Ovando permiso para entrar en el puerto de Santo Domingo al inicio de aquél, en víspera del terrible huracán que destruyó la armada que regresaba a España en el Canal de Mona donde perdió la vida el comendador Bobadilla. Terreros murió en Jamaica, el 29 de mayo de 1504 en acto de servicio al Virrey, defendiendo su vida ${ }^{26}$. Su trayectoria es bien aleccionadora de sus cometidos, y de cuánta fianza tenía el desconfiado don Cristóbal Colón de su persona, sirviendo de faraute en dos ocasiones cruciales para la gesta colombina. Pocas personas fueron más fieles.

24 CDD. 1 (nota 7), p. 624

25 Miss Alice reproduce el testimonio de Andrés del Corral en los Pleitos Colombinos de 1512. Corral, que entonces era Paje del Virrey, da cuenta de cómo se descubrió y tomó posesión de Paria. Éste dice que partieron de Santo Domingo con tres navíos, de los seis que habian salido de Castilla, y que Colón cfue a parar a la provincia de Parya, donde este testigo vyo como el dicho Almyrante al tiempo que halló la dicha prouincia, mandó salyr en tierra a vn Pedro de Terreros su capitán, e este testigo con otros salieron con él, e vio como la jente de aquella prouincia se espantaba de ver los xptianos como jente que nunca lo avian vysto... e alli en nombre del Rey e de la Reyna nuestros señores, tomaron la posesyón de la dicha prouyncia, la qual tomó el dicho Pedro de Terreros por mandado del dicho Almirante, porque él no saltó en tierra, porque estava malo de los ojos." [Gould, Nueva Lista (nota 17), pp. 382-383.] Esto le hizo pensar a la investigadora norteamericana que la razón de la elección de Terreros se debió por ser el Capitán de la nao capitana. Creo que ésta debe entenderse como resultado de la función de representación que tenian los continos, como fieles de su señor.

26 Gould, Nueva Lista (nota 17), pp. 376-378. El 5 de julio de 1517 , se proveyó un Real Mandamiento al tesorero Ochoa de Landa para que pagara a los herederos de don Cristóbal Colón distintas cantidades que dio de socorro a ciertas personas en el Cuarto Viaje. El Almirante habia socorrido con 16.195 maravedis a Pedro de Terreros [CDD. HI (nota 7), p. 2122.] 
Terreros como Diego Méndez pueden ser recordados como los criados por excelencia, arriesgando su vida y sus bienes, siempre en servicio de su señor.

Precisamente pensando en sus continos, el Virrey don Cristóbal Colón pidió y obtuvo una Real Provisión fechada en Medina del Campo a 30 de mayo de 1497, por la cual se le concedía el delegar en terceras personas el Poder Real de que gozaba en los asuntos de la negociación indiana ${ }^{27}$. La Real Provisión de 30 de mayo de 1497, dada en Medina del Campo, fue interpretada por el propio Cristóbal Colón, al anotar en el vuelto de la provisión: "que no se entienda en negoçio de las Yndias syn vna persona del Almirante» ${ }^{28}$. Esta medida, concedida por la Corona a Colón, le permitiría a éste último controlar a toda la administración en el Nuevo Mundo, o por lo menos participar en ella con los oficiales que hubiera elegido. ¿Quiénes mejor que los continos para cumplir con tal función y servicio al Virrey?

Pasemos, a otro contino que aparece en la «Relación», me refiero al ya mencionado Pedro de Arroyal. Su asiento en el dicho documento contable, dice:

«Pedro de Arroyal asentaronsele nueveçientos maravedis de sueldo cada mes por Escudero contino del Almirante don Xristoval Colon e montole aver

27 La dicha Real Provisión dice así: «Don Fernando e doña Ysabel [etc.] Por quanto al tiempo Don Xrptobal Colon, Nuestro Almirante del Mar Occeano, fue a descobrir las yslas e Tierra firme, que por la gracia de Dios Nuestro Señor falló, e se descobrieron en el dicho Mar Occeano a la parte de las Indias, se asentó con él, que obiere e guardase para sí, cierta parte de aquello que se fallare; e que agora por su parte Nos es soplicado, que porque mexor e más complidamente lo susodicho se guardase e compliese, que a nuestra merced plugiese mandar, que toda la Negocyacion e cosas que se obiesen de fascer e proveer en estos nuestros Reynos, thocante a la dicha Negocyacion de las dichas Indias, que se obiesen de fascer e fisciesen por una persona o personas nuestras con poder nuestro quen ello entendiesen o por él o por quien su poder obiere, xuntamente, porque ansi se podría mexor saber lo que resultaba de los gastos e pro e utilidad de la dicha Negocyacion, para que se podiese a él acudir con aquella parte que por los dichos asientos le pertenesce, e de que Nos, le fyscimos merced; o sobrello o proveyésemos como la nuestra merced fuese, e Nos, thobimoslo por bien; e por esta nuestra Carta mandamos a las personas que por nuestro mandado thienen o thobiesen cargo dentender en lo susodicho de aqui adelante, que lo fagan e negocien, xuntamente con la persona o personas quel dicho Almirante o quien su poder obiere, podiere e nombrare para ello, e non en otra manera; lo qual sentienda, theniendo el dicho Almirante de las Indias diputados, e nombrando persona o personas que por su parte o con su poder ello entiendan, e fasciéndonos saber como las tales personas están diputadas e nombradas por el dicho Almirante para entender con su parte en la dicha Negocyacion; de lo qual vos mandamos dar la presente firmada de nuestros nombres e sellada con nuestro Sello. Dada en la villa de Medina del Campo a treinta días del mes de Mayo, Año del Nascimiento de Nuestro Salvador de mill quatrusyentos e noventa e siete años. Yo el Rey. Yo la Reyna. Yo Fernan Alvares de Toledo, Secretario del Rey e de la Reyna... Ien las espaldas de la dicha carta decia: En la forma acordada Rodero, Doctor. Registrada, Alonso Pérez, Francisco Diaz, Chanciller.» [CODOIN. XXXVI (Madrid, 1881), pp. 152-154.]

${ }_{28}$ CDD. II (nota 7 ), pp. 963-965. 
desde XXVII de agosto de XCIII años hasta honze de junio de XCVI años que bolvio de las Yndias a Cadis $x x x U c l x x x$ maravedis tiene rresçibidos xiiiu maravedis quede que ha de aver xviUclxxx maravedis ha de aver mas el dicho Pedro de Arroyal en cuenta del sueldo de Bernaldino sastre del Almirante... siete mill maravedis los quales estan puestos a su cuenta del dicho Bernaldino» 29 .

A este Escudero contino, se refirirá la documentación como «criado del Almirante». En el sevillano Archivo de Indias, se conserva el asiento de los «Gastos que se hicieron en reparar las carabelas Santa Cruz y Santa Clara», de 1497. En el cual se dice:

"que gastó Pedro de Arroyal criado del Almyrante por su mandado en jornales y clauazon y cadenas de hierro y en coruatones y poleas y estopa $y$ azeyte y sebo y pez y otras cosas para las dichas dos carauelas, mill y seteçientos y tres maravedis segund está por menudo en la cuenta del dicho Pedro del Arroyal...» ${ }^{30}$.

Como se puede apreciar, la función de Arroyal en el apresto de las carabelas revela la versatilidad de cometidos de los Escuderos continos del Virrey. Aqui Arroyal, hombre de armas, es simplemente llamado criado. Al año siguiente, como ya hemos dicho, en el "Asiento de Pagos de las personas que fueron con sueldo a las Indias", se le llama Camarero del Almyrante. Cargo que debía ocupar por entonces en la Corte del Virrey de las Yndias ${ }^{31}$. La voz contino irá desapareciendo progresivamente de la documentación indiana dejando lugar a la de criado. Unos ejemplos nos lo proporciona Ots Capdequí quien Iocalizó cuatro documentos en los Archivos de Protocolos de Sevilla en que Diego Méndez aparece como "Contino del Almirante D. Diego Colón»32.

29 AGS. CMC. 1E. ff. $21 \mathrm{v}-22 \mathrm{r}$

30 CDD. Il (nota 7), p. 915.

3í En las páginas que Ots dedicó a los criados de Cristóbal Colón y de sus familiares, llama la atención la ausencia de referencia a los Continos, José María OTS CAPDEQuí, «La aportación Colombina del Instituto Hispano-Cubano de Historia de América», prólogo del libro de José DE LA ToRre y del CerRo, Beatriz Enríquez de Arana y Cristóbal Colón (Madrid, 1933), pp. 7-14, 18-20. Otro tanto ocurre con los "criados de la Virreyna de las Yndias", doña María de Toledo, que figuran como testigos en el testamento de Diego MÉNDEZ, en Valladolid, el 26 de junio de 1536, el fiel criado, Diego de Arana, Juan Diez Miranda de la Cuadra, Martín de Orduña, Lucas Fernández, Alonso de Angulo, Francisco de Hinojosa y Diego de Aguilera. Es de suponer que se trataba de continos, mas tanto Méndez como los demás dicen ser criados de la Virreina. [CDD. III (nota 7), p. 1702.]

32. OTS CAPDEQUí, «Aportación» (nota 31), p. 11. El más célebre de los criados colombinos, cruzó en canoa el Caribe entre Jamaica, donde se encontraba el Almirante con sus hombres muriéndose de hambre y enfermedad al final del Cuarto Viaje, y la Isla Española para pedir auxilio el 
Si se los calificaba a estos servidores especiales de continos, en un segundo momento se les llamó indistíntamente continos o criados, y a medida que pasó el tiempo se impuso la voz criados sobre la primera. Cabe preguntarnos cuántos de los numerosos criados de los Colón eran en realidad continos del Virrey ${ }^{33}$.

Comendador de Lares, Gobernador de las Yndias. Don Hernando Colón dice escuetamente: «Escogidas, en fin, dos canoas... mandó el Almirante, en Julio de 1503, que fuese en una de ellas Diego Méndez de Segura, Escribano Mayor de la Armada, con seis cristianos, y diez indios que bogasen; en la otra envió a Bartolomé de Fiesco gentilhombre genovés, con otra tanta compañia, para que luego Diego Méndez estuviese en la Española, siguiese derecho su camino a Santo Domingo...” [Hernando Colón, Historia del Almirante, Ed. de Luis ARRANz (Madrid, 1984), pp. 330-331.] En la "Relación de la gente y navíos que fueron con el Almirante..." en el Cuarto Viaje, Méndez aparece como "Escudero" [CDD. III (nota 7), p. 1709.] Junto a él aparecen otros, como Francisco de Farias, Pedro Gentil, Andrés Ginovés, Juan Jácome y Bautista Ginovés. El propio Méndez, en cambio, nos dejó ilustrado el trato del Almirante Viejo a sus Continos, en la relación del Cuarto Viaje que recoge su testamento, con fecha en Valladolid, de 26 de junio de 1536. Cuando el Almirante le pidió que cruzara el mar para conseguir ayuda, Méndez le respondió: «Señor muchas vezes he puesto mi vyda a peligro de muerte por salvar la vuestra y de todos estos que aquí estan y Nuestro Señor milagrosamente me a guardado, y la vida, y con todo no an faltado murmuradores que dizen que Vuestra Señoria me acomete a mi todas las cosas de honra avyendo en la compañia otros que las harian tan bien como yo; y por tanto parezeme a mi que Vuestra Señoria los haga llamar a todos y les proponga este negocio para ver si entre todos ellos abra alguno que to quiera enprender; 10 que yo dudo, y quando todos se hechen fuera, yo pondre mi vyda a muerte por vuestro servyçio como muchas vezes lo he hecho." $Y$ así se hizo al dia siguiente, siendo los demás de opinión que aquello era imposible «donde muy reçias naos ae avyan perdido andando a descubrir..." Entonces Méndez se levantó y dijo: "Señor, una vyda tengo no mas. Yo la quiero abenturar por servicio de Vuestra Señoria y por el byen de todos los que aqui estan, porque tengo esperança en Dyos Nuestro Señor que vista la yntençion con que yo lo hago, me librara como muchas otras vezes lo a hecho." Y añade Méndez, "Oyda por el Almirante mi determinaçion, levantose y abraçome y besome en el carrillo diziendo: "Bien sabía yo que no abya aqui ninguno que osase tomar esta ympresa sino vos. Esperança tengo en Dios nuestro señor saldreys della con vytoria como de las otras que abeys enprendydo". [CDD. III (nota 7), pp. 16991702.] Finalmente quiero recoger un último aspecto de Méndez que quizás nos ofrezca luces para conocer la vida y ocupación anterior de los continos del Virrey de las Yndias. Hasta 1494, Méndez estuvo al servicio de los Condes de Penamiacor, don Lope de Albuquerque y doña Leonor de Noronha, refugiados portugueses en Castilla. [Consuelo Varela, Cristóbal Colón. Retrato de un hombre (Madrid, 1992), p. 141.] Señálese que Penamacor murió asesinado en 1494 por orden de D. Joâo II en España, tras once años de persecución. Así era la venganza de El-Rei. El Conde era hermano del desventurado Almirante de Portugal muerto por $\mathrm{D}$. Joâo cuando la conspiración del Duque de Viseo. [István Szászdi León-Borja, "Las Paces de Tordesillas en peligro, los refugiados portugueses y el dilema de la guerra»: Las Relaciones entre Portugal y Castilla en la Época de los Descubrimientos y la Expansión Colonial, Ana María CARABIAS TORRES (Edit.), (Salamanca, 1994), p. 122.]. Diego Méndez sirvió a un primer amo que tenía muchos intereses en el mar, además de gozar de la merced de los Reyes. Cabe sospechar que Méndez era también portugués, dada la privanza que tuvo con don Cristóbal Colón era evidente que éste no albergaba dudas de su lealtad, otro indicio es su apellido que es muy corriente en Portugal. Su trayectoria nos señala que los continos que tomó Colón a su servicio en su mayoría debían ser criados experimentados al servicio de casas nobiliarias conocidas o de personajes de relieve. La investigación de sus pasadas vidas nos lo dirá en el futuro.

33 Por ejemplo, en el «Poder otorgado por Colón a favor de Francisco Bardi, para percibir el oro, joyas y otras cosas que le enviaran de las Indias", fechado en Salamanca a 10 de diciembre 


\section{EL SUELDO ATRASADO O LA ILUSIÓN DE RECOMPENSA}

El retraso en la paga de los criados no era privativo de la Contaduría Real. Tales descuidos también eran sufridos por los oficiales de la Casa del Virrey don Cristóbal Colón. La canina fidelidad de los continos del Virrey respecto de su señor no se veía correspondida con justicia y sus promesas, como las de su hijo Diego, quedaron muchas veces incumplidas.

Después de una vida de fatigas, sacrificios y servicios un Diego Méndez se desahogaba a sus hijos en su testamento dando fe de tales ingratitudes, formalizado en Valladolid a 26 de junio de 1536. Méndez, que debió ser el primer contino de don Cristóbal Colón, le había pedicio merced y premio. En el testamento el criado recuerda:

"Venido Su Señoria a la Corte, y estando en Salamanca en la cama enfermo de
gota, andando yo solo entendyendo en sus negoçios y en la restituçion de su
estado y de la governaçion para su hijo don Diego, yo le dixe ansi: «Señor, ya
Vuestra Señoria sabe lo mucho que os he servido y lo mas que trabaxo de
noche y de dia en vuestros negoçios: suplico a Vuestra Señoria me señale algun
galardon para en pago dello." Y el me respondio alegremente que lo señalase y
el lo conpliria, porque hera mucha raçon. Y entonçes yo le señale y suplique a
su Señoria me hiçiese merçed del ofiçio del alguaçilazgo mayor de la Isla
Española para en toda mi vyda. Y Su Señoria dixo que de muy buena voluntad
y que hera poco para lo mucho que yo avia servido; y mandome que lo dixese
ansi al señor don Diego su hijo, el qual fue muy alegre de la merçed a mi hecha
del dicho ofiçio; y dixo que si su padre me lo dava con una mano el con dos..."

Mas sucediendo a su padre en la Gobernación, don Diego incumplió la promesa, y llegado a Santo Domingo dio las varas de ese oficio a

\footnotetext{
de 1505, aparecen jurando los criados Diego Méndez «e Andrés e Fernando de Vargas criados del dicho Almirante"; posiblemente hermanos del contino del Virrey Francisco de Vargas e igualmente continos como Méndez. [CDD. III (nota 7), p. 1813.] Uno de estos casos es el de Bartolomé $D E$ FIESCO, quien le hemos visto - en la nota anterior - acompañando a Méndez en su misión de cruzar el Estrecho de Santo Domingo o Canal de Jamaica. Fieschi, llamado Flisco o Fiesco, era un gentilhombre genovés al servicio del Almirante, quien en el Cuarto Viaje fue Capitán de la nao Vizcaína. Cuando la crisis de Jamaica, Colón le el conducir una segunda canoa, que siguiendo a la de Méndez intentara cruzar el Caribe para pedir ayuda al gobernador Ovando. Fiesco debía regresar a Yamaye, el nombre taíno de la isla, para traer nuevas a los españoles y confirmarlos en que la ayuda estaba en camino. Debían acompañarles seis españoles y diez indios. Méndez despachó desde la Española una nao al mando de Diego DE SALCEDo con socorro. [Francisco MoRALES PADrón, Jamaica Española (Sevilla, 1952), pp. 20, 25.] Según don Antonio Ballesteros, los Fiesco eran un linaje conocido en Génova. Otra señal de que Fiesco era contino del Virrey don Cristóbal Colón es que figura como uno de los testigos de su testamento junto a otros criados, fechado el 19 de mayo de 1506 en Valladolid. Según el testamento éstos fueron: "Bartolame de Fiesco e Albar Perez e Juan dEspinosa e Andres e Fernando de Bargas e Françisco Manuel e Fernand Martinez criados del señor Almirante... » [CDD. III (nota 7), pp. 1824, 1825, 1828.]
} 
Francisco de Garay, criado del Adelantado de las Yndias, su tío, para que sirviese por su teniente. Esto ocurrió el 10 de julio de 1510. Terminaba Méndez diciendo:

«que si se me diera yo fuera el mas rico honbre de la ysla y mas honrrado, $y$ por no se me dar soy el mas pobre della, tanto que no tengo una casa en que more sin alquiler.»

Triste confesión del más diligente de los continos del primer y del segundo Virrey de las Yndias. Ello permite ver que no era tampoco entonces el que mejor servía el que más era premiado ${ }^{34}$.

Sigamos la suerte de algunos continos ya mencionados y de otros que nos quedan por narrar. El 25 de agosto de 1501 se libró una Real Cédula por la cual los Reyes ordenaban la entrega de quintales de palo de brasil a cinco continos del Virrey, estos eran: Pedro Hernández Coronel, Pedro de Terreros, Cristóbal de Torres, Diego Tristan y Pedro de Salsedo. Ese mismo día se expidió otra Real Cédula en los mismos términos para el también contino de Colón Gonzalo de Valdenebro. Y el mes siguiente, con fechas de 1 y 30 de septiembre, los Reyes firmaron otras sendas a favor de Juan de Molina y de Juan Cerón, igualmente continos del Virrey ${ }^{35}$. Nunca hubiéramos conocido con seguridad la naturaleza de tales quintales de no ser porque los Reyes despacharon otra Cédula a favor del Contino Real Alonso Sánchez de Carvajal el 17 de agosto de 1501 .

\section{DOS VIDAS NOTABLES: JUAN CERÓN Y GARCIÁ TROCHE.}

Ninguna noticia conservábamos del pasaje al Nuevo Mundo de estos dos individuos tan importantes para la Historia de Puerto Rico. Una vez más la «Relación de Cuentas de Salarios Debidos» nos ofrece respuesta a estos misterios. Cerón figura en el siguiente asiento:

34 CDD. III (nota 7), pp. 1699-1702.

35 Consultando en el Fichero de Personas del legado de Miss Alice Gould, custodiado en la Sala Gould de la Real Academia de la Historia en Madrid, encontré una ficha de escrita por Miss Alice que recoge la Real Cédula a favor de Juan Cerón, que me permitió hallar las otras en el mismo Libro 5 de la Sección Cámara de Castilla Cédulas en el Archivo General de Simancas (AGS). Todas se encuentran reproducidas por primera vez en el Apéndice Documental de este trabajo. 
«Juan Çeron asentaronsele nueveçientos maravedis por contyno del Almirante don Xtoval Colon e montole aver desde dos dias de setiembre del año de XCIII años fasta XI de Junio de XCVI años que voluio de las Yndias a Cadis $x x x U$ tiene rresçibidos en dineros e en debdas $x U / x x$, asy quedan que ha de aver $x i x U d \operatorname{cccc} x \times x{ }^{36}$.

Cerón había facilitado de su sueldo dinero a otros como Gonzalo de Çamora, tejedor, Bartolomé de Molina, espadero, Alonso Peres Roldán, piloto de la Gallega, y Antonio de Cárdenas, labrador ${ }^{37}$. Entre 1497 y 1510 casi queda un vacío, a excepción de la cédula en su favor de 30 de septiembre de 1501 no tenemos noticias suyas ${ }^{38}$. El 30 de septiembre de 1501 una Real Cédula le otorgó algo de palo de brasil por sus servicios. Por lo menos sabemos que viajó en 1493 en compañía del Virrey como su contino. De Juan Cerón tenemos una noticia importante, su hermano Jorge era cuñado del Secretario del Rey don Francisco de los Cobos. Jorge Cerón estaba casado con una hermana de doña María de de Mendoza, hija del Adelantado de Galicia, don Juan Hurtado de Mendoza, llamada doña Catalina de Mendoza ${ }^{39}$. Los hermanos Cerón eran oriundos de Baeza, población vecina a Úbeda en el Reino de Jaen ${ }^{40}$. Por lo que se

${ }^{36}$ AGS. CMC. 1E. f. 5v. La edición de Montserrat LEón yerra lamentablemente al transcribir este asiento, escribiendo "e montole aver desde dos dias de setiembre del año de xviij años que bolujo de las yndias a cadjs..." [María Montserrat GuerRERO, "Transcripción del documento Gente del Segundo Viaje» (nota 19), p. 64.]

37 AGS. CMC. 1E. f. 5v-6r.

38 Véase el Apéndice Documental.

39 Giménez FeRnández, El plan Cisneros-Las Casas para la Reformación de las Indias, I (Sevilla, 1953), p. 89. El matrimonio de don Francisco de los Cobos con doña María de Mendoza se acordó por contrato fechado a 19 de octubre de 1522, entre los padres de la novia que eran Condes de Ribadavia y el futuro consorte, que ya era Secretario Real y Miembro del Consejo de Su Majestad. Ese mismo día se celebraron los esponsales. [Hayward KENIsTon, Francisco de los Cobos Secretario de Carlos V, ed. española (Madrid, 1980), p. 73.] Pero tal enlace tuvo que ser anterior al de Jorge Cerón. Giménez Fernández cita un documento de 1530 por el cual Jorge Cerón, vecino de Baeza, y estante en Sevilla, otorgaba poder a su esposa doña Catalina de Mendoza para cobrar en España y de las Indias, pero ello no supone una antigüedad del matrimonio mucho mayor a aquella fecha. Soy de opinión que tal enlace debió gestarse después de 1522 cuando el "pariente mayor» realizó el suyo emparentando con la Casa de Ribadavia.

40 En cambio para BoYD-BOWMAN era natural de Écija, y recoge con correción que pasó a Yndias con el Almirante en 1493, siguiendo a Schäfer. [Peter BoYD-Bowman, índice geobiográfico de más de 56 mil pobladores de la América hispánica 1. 1493-1519 (México, 1985), p. 107. Ernesto Schäfer, indice de la Colección de Documentos Inéditos de Indias (Madrid, 1946), p. 111.] Las Casas es el cronista que atribuye a Cerón ser originario de Écija. [Fray Bartolomé DE LAS CASAS, Historia de las Indias, Texto y estudio de Juan PÉREZ DE TUdELA y Emilio LóPEz OTO, II (Madrid, 1961), p. 125.] La única fuente en que Cerón declara haber participado en el Segundo Viaje, aparte de la Relación, se encuentra en su testimonio en la Probanza tomada en Puerto Rico por mandato de don Diego Colón en 14 de septiembre de 1514. Así lo respondió repetidamente a la segunda, tercera y cuarta pregunta. [CODOIN. 2. ${ }^{a}$ serie, 7 (Madrid, 1892), p. 428.] 
debe presumir que Cobos y los Cerón eran deudos cercanos, y que los segundos se verían amparados por el primero desde que llegara a la Corte a trabajar junto a los secretarios de los Reyes allá por 1503. Por entonces Juan Cerón ya había entrado al servicio del Virrey de las Yndias. No sabemos a ciencia cierta cuándo regresó al Nuevo Mundo después de 1496.

Por la Probanza de 14 de septiembre de 1514, que don Diego Colón hizo tomar en Puerto Rico para los Pleitos Colombinos, el testigo Juan Cerón dijo "que puede aver quarenta e cinco años, poco más o menos..." Lo que significa que habría nacido por 1469 y que en 1493 tenía 24 años, edad en que debió entrar a servir al Almirante-Virrey.

Cerón era bien considerado pues cuando don Diego Colón quiso imponer su autoridad virreinal en San Juan Bautista, frente a Juan Ponce de León - a quien don Fernando el Católico había nombrado Gobernador de la Isla estando ésta en litigio - envió a Juan Cerón por su Alcalde Mayor a aquélla. Le acompañaban para aquel menester su hermano Martín Cerón, con cargo de Alguacil Mayor de la Isla, García Troche, contino del Virrey don Cristóbal que fue a las Yndias en 1493, Alonso de Cea, quien había sido grumete en el Cuarto Viaje del Almirante viejo y que había pasado a ser "criado del Almirante Don Cristóbal Colón" y otros ${ }^{41}$. Cerón fue recibido en el oficio el día 28 de octubre de 1509. Miguel Díaz de Aux pasó de Santo Domingo a Puerto Rico pocos meses después, en abril; había sido nombrado hacía poco Alguacil Mayor de la Isla de San Juan por el Virrey, don Diego Colón.

Juan Cerón era el oficial más importante de San Juan después del gobernador Juan Ponce, apartir de que tomó la vara de justicia empezó a repartir los indios boricuas entre los vecinos y pobladores estantes. Incluso a Ponce le quitó los caciques con que cogía el oro de la compañía que tenía con el Rey. Don Fernando por medio de dos Reales Provisiones reforzó los poderes de Ponce nombrándole Capitán Gobernador de San Juan Bautista y a la vez mandaba a quienes tuvieran las varas de la justicia que las entregaran al dicho Juan Ponce. Ello le permitió destituir a Cerón y a Miguel Díaz, después de haber enviado traslado de ellas al Virrey. Por esos días había llegado don Cristóbal de Sotomayor, antiguo Secretario Real y letrado, quien - como creía Murga- debió ser el responsable de que Ponce tomara la decisión de prender al contino. El Alcalde Mayor tomó la Provisión, besola y la puso sobre su cabeza en señal de obedien-

41 Así figura en los protocolos notariales sevillanos. [Ots, «Aportación» (nota 31), p. 7.] Igualmente consúltese CDD. III (nota 7), pp. 1709, 1804, 2105.] 
cia, quedando al poco libre. Ponce otorgó la Alcaldía Mayor de la Isla al gallego Sotomayor, quien remitió a Cerón y al Alguacil y aun Teniente de Alcalde presos al Rey con procesos falsos según declarara don Diego Colón ${ }^{42}$. El Rey había conseguido socavar la autoridad del Virrey en la Isla de San Juan, al remover a su contino, y colocar en su lugar al bachiller Sotomayor cuya única misión en el Nuevo Mundo era la de informar conforme a derecho a Ponce y mantener a la antigua Boriquén bajo control del Rey don Fernando.

El 5 de mayo de 1511 el Consejo falló el pleito entre el Rey y don Diego Colón, a favor del segundo. Entonces, don Fernando, a día 15 del mes, proveyó para que Ponce cesara en su oficio, y entregara las varas de la justicia a Juan Cerón y a Miguel Díaz, a quienes había enviado presos a España. Cerón recuperó por entonces la Alcaldía Mayor y Díaz de Aux el oficio de Alguacil Mayor. Podemos decir que Cerón era el criado más importante para los Colón por entonces.

¿Y Troche? Troche figura en la «Relación de Cuentas de Salarios Debidos». Hasta ahora esto nos era desconocido. El asiento dice:

«Garcia Troche asentaronsele nueveçientos maravedis de sueldo cada mes por Escudero contino del Almirante don Xtobal Colon e montole aver desde $X X V I I$ de agosto de $X C I I I$ años hasta $V$ dias de noviembre de XCVI años que boluio de Yndias a Cadiz" ${ }^{43}$.

Por tanto debemos presumir que por 1493 tendría unos veinte años, como mínimo, lo que remontaría su de nacimiento a fechas cercanas a 1470, y por tanto la misma edad aproximada de Juan Cerón ${ }^{44}$. Troche nació en una noble familia de Olmedo, de regidores de «los linajes de dentro", debió acercarse a Colón gracias a Fonseca, cuyo hermano era

\footnotetext{
42 Vicente Murga Sanz, Juan Ponce de León fundador y primer gobernador del Pueblo Puertorriqueño, Descubridor de la Florida y del Estrecho de Bahamas (Río Piedras, 1971), pp. 47-49. Luis Arranz, Don Diego Colón (Madrid, 1982), pp. 294.

43 Foja 7r. Alice Gould leyó, en Iugar de GARcIA TROCHE, «Roche o Trocha, Garcia de». [Gould, Nueva Lista (nota 17), p. 380.]

44 Dice Tió que el padre de García Troche se llamó Martín de Olmedo, y que era Contino del Rey. [Aurelio Tió, Nuevas fuentes para la Historia de Puerto Rico (San Germán, 1961), p. 542.] Lo cierto es que consta que antes de 1495 Vasco y García Troche, vecinos de Olmedo e hijos de Velasco Sanz Troche entregaron a los frailes mercedarios la capilla de la Magdalena, que poseían sus antepasados, en el Monasterio de Nuestra Señora de la Merced de aquella villa y a cambio recibieron un lugar para poner el bulto funerario de su padre en medio de la capilla mayor de la iglesia vieja del convento, como en su capilla habian tenido, además del privilegio de poner sus armas en las paredes exclusivamente y que nadie más se pudiese enterrar en ella a excepción de Diego de Soto, Gonzalo y Álvaro de Buitrago que ya tenian sus sepulturas. [Pilar MatamaLA y Jesús URREA, La nobleza y su patronato artístico en Olmedo (Valladolid, 1998), p. 15.]
} 
señor de Coca y grande poder en la región. Sus antepasados se enterraron en la capilla mayor de la iglesia conventual de los mercedarios de Olmedo, cuya construcción todavía existe en la Plaza de Santa María del Castillo y en cuyos muros exteriores todavía se conservan dos escudos con las tres truchas de la familia. La casa de los Troche se encontraba en la misma plaza, desgraciadamente hace pocos años fue derruida, de la cual queda solamente la panera del siglo XVI con el escudo de la familia. Años más tarde, al haber alcanzado bienestar y honra, enviará dineros para el convento de Nuestra Señora de la Merced de su villa natal en cuya iglesia estaban enterrados sus deudos y ancestros.

El 5 de julio de 1517 doña Juana y don Carlos ordenaron al tesorero Ochoa de Landa que pagara a los herederos de Cristóbal Colón los maravedís con que éste había socorrido a distintas personas en el Cuarto Viaje, adelantándoles cantidades varias; en tal Real Mandamiento hay una partida que dice:

"A Garçia Tyoche (sic), con otros mill e seysçientos e noventa y dos maravedis y medio..." ${ }^{45}$.

Lo que prueba que Troche acompañó al genovés en aquellas duras jornadas. En el mismo documento aparece el contino Terreros como ya he señalado. Es posible que Cerón también haya estado al lado del Almirante entonces, cumpliendo las obligaciones derivadas de la continería. Ello justificaría que don Diego Colón tuviera a aquellos dos continos de su padre como los criados más idóneos en quien confiar el establecimiento de su autoridad en la antigua Boriquén.

Los Troche debian tener diversos conductos de acceso a la Corte, tanto por medios eclesiásticos como por haber continos Reales entre los suyos, además, estaban emparentados con las más notables familias olmedanas y de las villas de los alrededores ${ }^{46}$.

\footnotetext{
$45 \quad C D D$. III (nota 7), p. 2122

46 Un Francisco TROCHE era por 1498 «familiar» del Cardenal de Valencia, es decir, el equivalente de Contino DE CESAR BORJA. El Rey Fernando pidió al Cardenal que Troche renunciara a un derecho que el Papa le habría proveído sobre el monasterio benedictino castellano de San Loal del Pinar por muerte de micer Esteban de Portillo. [Antonio de la TORRE, Documentos sobre las Relaciones Internacionales de los Reyes Católicos, VI (Barcelona, 1966), pp. 107, 108.] Sí habían Continos Reales en la familia Troche. Uno de ellos se llamaba Diego Troche, "Contino de Sus Magestades" quien en compañía del Contino del Presidente del Consejo Real Francisco de Saavedra, y de Sebastián Rodríguez Hernán Ximénes Procurador de Causas en el Consejo de Yndias, fue apoderado de su deudo Gracia Troche en 1540. Así consta en el otorgamiento y sustitución de poderes que hizo el doctor lohan Ximénez de Monreal, vecino de Olmedo, en calidad de
} 
Cuando en 1511 Cerón fue restablecido en San Juan, García Troche era Contador, oficio que ocupó más de tres años durante los difíciles días de la sublevación indígena de la isla. El Rey le premió con un regimiento. Por entonces Cerón, Díaz de Aux, los oficiales reales y Ponce habían acordado el cooperar y olvidar los tiempos pasados para el bien de la Isla. El alzamiento de los indios, con la muerte de Sotomayor, probó cuán importante era el permanecer unidos. Las noticias de la tragedia llevaron a don Fernando a demandar tal actitud de sus oficiales, a partir del 21 de julio de 1511 en que ordenó a Ponce que entregara las varas de la justicia a Cerón y a Díaz de Aux y que regresara a España, con el fin de evitar una guerra civil entre los españoles ${ }^{47}$.

García Troche recibió por Real Provisión con fecha de 19 de octubre de 1514 , en Valbuena del Duero por el Rey don Fernando y la Reina doña Germania, el nombramiento de Regidor perpetuo de la villa de San Germán ${ }^{48}$. La Reina doña Juana proveyó, a petición de Gaspar Troche, el que le fueran acrecentados a García los indios que tenía encomendados por los muchos servicios que había prestado a su Padre ${ }^{49}$.

La carrera de García Troche fue ascendente. Juan Ponce tenía cuatro hijos, Luis, Juana - la mayor, María e Isabel. García casó con Juana, su hermano Gaspar con María, e Isabel, ya muerto su padre, casó con el li-

apoderado de García Troche, vecino y regidor de la ciudad de San Juan de Puerto Rico. [Tió, Nuevas fuentes (nota 44), p. 437] Diego Troche, vecino de Olmedo, tiene su sepultura en la iglesia mudejar de San Andrés de aquella villa, junto al arco mayor, al lado de la Epístola. Don Diego Troche y su mujer doña María de la Palma habían fundado su mayorazgo en 1561. [MATAMALA Y UrreA, La nobleza (nota 44), pp. 95-97.] Monreales, Velázquez y Saavedras eran parientes de los Troche naturales de Olmedo.

47 Murga, Juan Ponce (nota 42), p. 74.

48 Vicente Murga Sanz, Cedulario Puertorriqueño, I (Río Piedras, 1961), pp. 335.

49 La dicha Real Cédula hace relación de los servicios de García Troche en los siguientes términos: "Nos hiso rrelaçion quel dicho Garcia Troche su hermano fue y es de los primeros pobladores de la dicha ysla e en ella nos auia seruido con su persona e honbres a su costa asy en las guerras de la dicha ysla como en el oficio de Contador mas de tres años en tienpo que los indios estauan de guerra e no seruia syn ningun interese que por el dicho ofiçio se le syguiese e que en este postrer rrepartymiento de Indios que en la dicha ysla se hizo se le encomendo vn Cacique que se dize Maboavabres con $L X X X\left({ }^{*}\right.$ por) Indios e naborias en que fue visitado e diz que despues de fecho el dicho rrepartimiento el Rey nuestro señor padre e ahuelo que aya Santa Gloria le hizo merçed al dicho su hermano en rremuntraçion de lo que auia seruido de vn rregimiento en la dicha ysla con lo qual mando que le fuesen encomendados çient yndios segun que cada vno de los rrecebtores de la dicha ysia los tenian e que por ser fecho el rrepartymiento de los yndios de la dicha ysla en el tienpo que la dicha prouisyon llego no vbo efeto de cunplirse el numero de los dichos çien Indios supliconos sobre ello proveyesemos mandando que sobre los dichos ochenta yndios que asy en el dicho rrepartymiento le auian sydo encomendados en el dicho Caçique le mandasemos cunplir el numero de los dichos çien Indios o como la nuestra merced fuese e visto $\left({ }^{*} e\right.$ ) fue acordado que deviamos mandar dar esta nuestra Carta para vosotros en la dicha rrason e Nos touimosio por bien.» (AGI. Indiferente General 419, L. 6.) 
cenciado Antonio de Gama, Juez de Residencia y Gobernador de la Isla, a finales de 1520. Ponce murió al año siguiente en la Habana, por una mala herida recibida de los indios de la Florida. El Adelantado había dejado por albaceas testamentarios, curadores y tutores de sus dos hijos menores, Luis y María, a su yerno García Troche y a Juan de Soria. Los cuales pidieron el 9 de octubre de 1521 la declaración como tales al Teniente de Gobernador Pedro Moreno. El 4 de noviembre de 1521, Troche y Soria, dieron poderes a Gaspar Troche, casado con doña María Ponce de León, y a Jerónimo Velas, vecino de Olmedo, poderes de procuración para obtener de los Reyes el que se hiciera merced en don Luis Ponce de León de los oficios de su padre, el Adelantado. Si bien Sus Altezas se la concedieron, lo condicionaron a que no fuera "clérigo de corona". Don Luis decidió entrar en religión, renunciando sus derechos a favor de su cuñado, García Troche, que se convirtió en Regidor de la ciudad de San Juan de Puerto Rico de derecho, pues ya lo venía haciendo de hecho desde los inicios de 1525 con autorización real ${ }^{50}$. Y así García Troche se convirtió en el heredero principal de Juan Ponce de León.

La muerte del antiguo contino del Virrey don Cristóbal Colón ocurrió con anterioridad al año de $1546^{51}$. Y si consideramos que nació por 1470 , debía tener algo más de setenta años de edad. Su vida es quizás la más exitosa trayectoria a la que un contino virreinal podía aspirar a alcanzar.

Las relaciones de privanza, parentesco y clientela entre los oficiales públicos indianos y la Corte, como su integración en la naciente sociedad del Nuevo Mundo son necesariamente objeto de estudio de quien pretenda conocer la Administración Española en las Yndias. Sin olvidar el marco jurídico institucional, deberá el investigador, que tenga este propósito, bucear en las más variadas fuentes para reconstruir los condicionantes que motivaron - en una relación causal - los efectos conocidos de este desarrollo histórico.

50 Murga, Juan Ponce (nota 42), pp. 251-253.

51 Entonces, el 24 de agosto de 1546, desde Guadalajara, el Rey proveyó en Juan Ponce Troche de León, la tenencia de la Fortaleza de Puerto Rico. Tenencia que tuvo hasta la muerte su padre, Garci Troche, y porque no tenia edad suficiente entonces la ocupó Jerónimo de Lebrón con 10.000 maravedís anuales, hasta que alcanzara la mayoría de edad. Aunque entonces no la había cumplido la muerte de Lebrón llevó al Rey a concedérsela con 300.000 maravedís de salario. [DUQUeSA DE BERWick y ALBA, Nuevos Autógrafos de Cristóbal Colón y Relaciones de Uitramar (Madrid, 1902), p. 56.]. 


\section{APÉNDICE DOCUMENTAL}

\section{Real Cédula a favor de Pedro Hernández Coronel, Pedro de} Terreros, Cristóbal de Torres, Diego Tristán y Pedro de Salzedo concediéndoles el pago de sus servicios en palo de brasil; de 25 de agosto de 1501. (AGS. Cámara de Castilla - Cédulas, Libro 5, asiento 1019, f. 220r.)

Pedro Hernandes Coronel e otros / El Rey e la Reyna. Por quanto por otra nuestra Çedula cometida a don Xtoual Colon / nuestro Almirante del Mar Oçeano ovimos hecho merçed a vos Pero Hernandes Coronel / e a vos Pedro de Terreros e a vos Xtoual de Torres e a vos Diego de Tristan e a / vos Pedro de Salsedo de de LX quintales de brasyl / cada vno de vos la canti/dad en esta guisa: /

- A Pedro Hernandes Coronel XX quintales de brasil - XX. I

- A Pedro de Terreros $X$ quintales - X. I

- A Xtoual de Torres otros $X$ quintales - X. I

- A Diego Tristan otros $X$ quintales - X. I

- A Pedro de Salsedo otros X quintales - X. I

- Agora por vuestra parte nos es fecha rrelaçion quel dicho Almirante ny otra / persona no vos dio ni entrego los dichos LX quintales e Nos suplicastes / que mandasemos que la dicha merçed oviese efeto çerca de lo qual por nuestro man/dado fue avida informaçion e porque por ella paresçe que hasta agora / no vos a sydo dado el dicho brasyl ni parte alguna del touymoslo por bien / e por la presente vos hasemos merçed de los dichos quintales de brasyl e a cada / vno de vos la cantia susodicha por lo que Nos abeys seruido en las Yndias / con tanto que rrequirays cada vno de vos o quien vuestro poder oviere a los / mercaderes con que Nos avemos mandado tomar çierto asyento ( $\left.{ }^{*} \mathrm{sob}\right)$ çerca del dicho / brasyl que lo toman al presçio e segun e de la manera que se les de el otro / nuestro brasyl de las dichas Yndias en el numero de los quintales que ( ${ }^{*}$ son obligados) por / el dicho asyento son obligados a traher que vos lo pagaren al dicho / presçio e sy no lo quisieren tomar segund dicho es vos damos liçençia e fa/cultad para que podays cargar e traher los dichos LX quintales / de la Ysla Española cada vno de vos o quien vuestro poder oviere e lo venda / a quien quisieredes e por bien tovieredes e mandamos al nuestro Governador / ques o fuere o a otros qualesquier justicias de las dichas Yndias que en ello / no vos pongan enbargo ni ynpedimento alguno. Fecha en Granada a XXV / dias de agosto de / IUDi años. Yo el Rey. Yo la Reyna. Por mandado etc. / 
11. Real Cédula de 25 de agosto de 1501 a favor de Gonzalo Valdenebro, del mismo tenor, en pago de sus servicios. (AGS. Cámara de Castilla - Cédulas, Libro 5, asiento 1020, f. 220v.)

Gonzalo de Valdenebro / El Rey e la Reyna. Por quanto por otra nuestra Çedula cometida a (*don Françisco) / Xtoual Colon nuestro Almirante del Mar Oçeano hisymos merçed a vos Gonzalo / de Valdenebro juntamente con otras personas de $\mathrm{X}$ quintales de brasyl / e agora por vuestra parte Nos es fecha rrelaçion quel dicho Almirante ni otra / persona en su nonbre no vos dio ni entrego el dicho brasyl e Nos / suplicastes que la dicha merçed oviese efeto e porque Nos somos / ynformados que hasta agora no vos a sydo dado el dicho brasyl e / ni parte alguna dello touimoslo por bien e por la presente vos / fasemos merçed de los dichos $X$ quintales de brasyl por lo que Nos haveys / seruido en las Yndias con tanto que vos o quien vuestro poder oviere / rrequirays a los mercaderes con que Nos avemos mandado tomar çier/to asyento çerca del dicho brasyl que lo tome al preçio segun / e de la manera que se les da el otro nuestro brasyl / en las dichas Yndias e / en el numero de los quintales que por el dicho asyento son obligados a / traher e vos lo paguen al dicho preçio e sy no lo quisieran / tomar dandoselo segun dicho es vos damos liçencia e facultad / para que podays cargar e traher los dichos $X$ quintales de brasyl de la Isla Española vos o quien el dicho vuestro poder ouiere, e lo vender a quien quisieredes e / por bien tovieredes al preçio que aqui se vos ygualardes e mandamos al / nuestro Governador que es o fuere e a otros qualesquier ( ${ }^{*}$ personas) justiçias de las Yndias / que en lo susodicho no vos pongan enbargo ni inpedimento alguno otro / que la dicha merçed primera se tiene a Pedro de Valdenebro porque segund paresçe por vna / fee de Ximeno de Briuiesca el dicho nonbre de Pedro fue puesto por yerro e a/via de ser Gonzalo. Fecho en Granada a XXV de agosto de IUDi años e por virtud de / otra qualquier nuestra nomina o Çedula vos mando dar los dichos / $X$ quintales de brasil $e$ ${ }^{*}$ e) vna vez e no mas lo qual hased tomandolo / rrason dello Juan Lopez mi Contador. Yo el Rey. Yo la Reyna. Por mandado etc. /

III. Real Cédula de 1 de septiembre de 1501 a favor de Juan de Molina. (AGS. Cámara de Castilla - Cédulas, Libro 5, asiento 1042, f. 225v.)

Juan de Molina / Primero dia de setienbre de IUDi años se dio vna Çedula para que den / en las Yndias a Juan de Molina X quintales de brasyl / que por otra Çedula le mando dar V.M. por lo que siruio en las Yndias con tanto que 10 / venda a los mercaderes con quien esta fecho conçierto al preçio / segund se le da lo de V.M. [...] esto o estan asentados en estenso atras. / 
IV. Real Cédula de 3 de septiembre de 1501 a favor de Alonso Sánchez de Carvajal. (AGS. Cámara de Castilla - Cédulas, Libro 5 , asiento 1078, f. 233r.)

Alonso Sanches de Carvajal / El Rey e la Reyna etc. / Por quanto por otra nuestra Çedula cometida a don Xtoual Colon / nuestro Almirante del Mar Oçeano hisymos merçed a vos Alonso Sanches de Carvajal juntamente con otras personas de XX quintales de brasyl e agora por vuestra / parte Nos es fecha rrelaçion que el dicho Almirante ni otra persona en su nonbre / no vos dio ni entrego el dicho brasyl e Nos suplicastes que la dicha merçed uviese / efecto e porque Nos somos ynformados que hasta agora no vos ha / sydo dado el dicho ( ${ }^{*}$ pa) brasyl ny parte aguna della touimoslo por bien / e por la presente vos hasemos merçed de los dichos $\mathrm{XX}$ quintales de brasyl / por lo que Nos aveys seruido en las Yndias con tanto que vos o quien / vuestro poder ouiere rrequirays a los mercaderes con quien Nos avemos / mandado tomar çierto asyento çerca del dicho brasyl que lo tomen al / preçio e segun e de la manera que se les da el otro nuestro brasil de las dichas yslas / e en el numero de los quintales que por el dicho asyento son obligados $\left({ }^{*} e\right) /$ a traher e vos lo paguen al dicho preçio e sy no lo quisieran / tomar dandoselo segun dicho es vos damos poder e facultad para que podays / traher e cargar los dichos XX quintales de brasyl de la Ysla Española / e vos o quien vuestro poder lo vender a quien quisierdes e por bien to/dos al preçio e segun que mejor vos ygualades e mandedes al nuestro / Governador e otras qualesquier justiçias e personas que agora son / e serna (sic) de las dichas Yndias que en lo susodicho no vos pongan enbargo / ni ynpedimento alguno e entendiese que por esta nuestra Çedula e por / otra qualquier nuestra nomina o Çedula que para lo susodicho ayamos dado no se / vos a de dar mas de los dichos XX quintales de brasyl lo qual has de tomar de la / rrason dello Juan Lopez nuestro Consejero. Fecho en Granada a tres de setienbre de IUDi años. Yo el / Rey. Yo la Reyna. Por mandado etc. /

V. Real Cédula de 30 de septiembre de 1501 a favor de Juan Çeron. (AGS. Cámara de Castilla - Cédulas, Libro 5, asiento 1182, f. 264r.)

Juan Çeron / En Granada a XXX de setienbre de IUDi años se dio vna Çedula / conforme a las pasadas para que den a Juan Çeron $X$ quintales de brasyl que por / otra Çedula se le mandaron dar por lo que siruio en las Yndias con tanto / que lo venda a los mercaderes al preçio que se le dio lo de V.M. y en el numero / de aquello. / 